(2) Open Access Full Text Article

\title{
Synergistic Dose Permutation of Isolated Alkaloid and Sterol for Anticancer Effect on Young Swiss Albino Mice
}

\author{
Nada H Aljarba',* \\ Huma Ali iD $2,3, *$ \\ Saad Alkahtani (iD ${ }^{4}$ \\ 'Department of Biology, College of \\ Science, Princess Nourah bint \\ Abdulrahman University, Riyadh, Saudi \\ Arabia; ${ }^{2}$ Department of Chemistry, \\ Maulana Azad National Institute of \\ Technology, Bhopal, 462003, MP, India; \\ ${ }^{3}$ Pinnacle Biomedical Research Institute, \\ Bhopal, 462003, MP, India; ${ }^{4}$ Department \\ of Zoology, College of Science, King Saud \\ University, Riyadh, I 145I, Saudi Arabia \\ *These authors contributed equally to \\ this work
}

Introduction: Synergy is defined as an interaction of some substances that cooperate to give rise to the combined effect greater than the sum of their individual effects. It is a natural strategy that has evolved by nature to more efficacy with low cost.

Methods: This study is designed to evaluate the chemopreventive effect of a combined drug sample which is prepared by mixing an equal portion of stigmasterol and palmatine isolated from Azadirachta indica and Tinospora cordifolia respectively at a concentration of $100 \mathrm{mg} /$ $\mathrm{kg}$ and $200 \mathrm{mg} / \mathrm{kg}$ body weight during the whole concentration.

Results: At the end of the study, it was found that this combined drug sample decreased the number of tumors and their size. This drug significantly reduced the serum level of glutamate pyruvate transaminase, alkaline phosphatase, glutamate oxalate transaminase, and bilirubin and enhanced the level of oxidative enzyme level of glutathione, superoxide dismutase, and catalase, and inhibit the level of lipid peroxides.

Discussion: The result suggests that combined drug samples exhibit a chemopreventive effect which is better than the effect of individual drugs (stigmasterol and palmatine).

Keywords: synergistic effect, anticancer, palmatine, stigmasterol, Swiss albino mice

\section{Introduction}

Synergism plays a key role in the therapeutic efficacy of herbal medicine and its formulation. It is presumed to occur if the active concentration of ingredients in the combination is considerably reduced or the effects of ingredients in combination are considerably increased concerning that of each distinct ingredient. This cannot be easily well known from additive effects and commonly rely on high limits of deviation. ${ }^{1}$ The mechanism of action of various herbal medicines is still unidentified and there are several examples of a total herb extract screening an enhanced effect than the same dose of an isolated compound. ${ }^{2}$ It will possibly implicate a comprehensively new line, for instance by examining mechanisms using new molecular biology methods for the isolated ingredients individually and in combination, which is already described by Wagner. ${ }^{3}$ In this admiration, we are only at the creation of a remarkable novel study, which must shed light on how exactly these therapies effort and finally consequence in condensed side effects and an improved therapeutic accomplishment. ${ }^{4}$ Overall, synergistic effects are measured to be constructive, with the low doses used supposed as a value, even though it is noticeable that there may also be undesirable features. ${ }^{5}$
Correspondence: Huma Ali Department of Chemistry, Maulana Azad National Institute of Technology, Bhopal, 462003, India

Email humali.manit@yahoo.com 
The advance to repress the progression of carcinogen by the herbally occurring agent is promising because this approach has been valuable against the high incidence of low survival rate of most of the cancers. In this regard, the naturally occurring compounds such as alkaloids, flavones, retinoids, antioxidants, etc. inspired by persons are getting more and more awareness. ${ }^{6}$ The drug obtained from different medicinal herbs is used to prove several pharmacological applications. At the recent time scientist intended to determine new drugs from higher plants lead to the improvement of drugs like reserpine, which is isolated from Rauwolfia serpentina used for the medication of hypertension and various other medical problem like insomnia. Vinblastine and vincristine, obtained from Catharanthus roseus by using different isolation methods have been used for the prevention of various diseases like cancer. These isolated drugs were found to be alkaloids from their structure. Thus, isolation, purification, and structural elucidation of the active chemical constituent will give much stress to the biological significance of medicinal plants. ${ }^{7}$ Alkaloids and many other chemical compounds such as flavonoids, tannin, saponin, phytosterols, etc. isolated from different medicinal plants are used for the treatment of various diseases like cancer and many more. ${ }^{8}$

In traditional medications methods, combinations of plants are practiced instead of single species and so the condition is even further difficult, even though very similar perceptions of synergy relate, that is a blend of the dual or more species contributes an improved result than either species on its individual. "Triphala" is a distinguished polyherbal preparation (Churna) in ISM mainly in Ayurveda meanwhile early period, used for various therapeutic resolutions. ${ }^{9}$ This preparation was organized as powdered preparation, in the permutation of parched fruits of Terminalia bellirica, Emblica officinalis, and Terminalia chebula, in the same ratio as defined in the Ayurvedic Formulary of India (AFI). Traditionally, this formulation has been given as first-line prevention for various diseases such as a laxative in the detoxifying agent of the colon, food digestive problems, chronic constipation and rejuvenator of the body, etc. ${ }^{10}$ The abovementioned three fruits were varied based on their rich polyphenol portion present therein and combined as a formulation which is the established example of the synergistic combination.

The current research is an effort to recognize the synergistic effect of isolated palmatine from Tinospora cordifolia and stigmasterol from Azadirachta indica for anticancer activity.

\section{Materials and Methods \\ Extraction, Isolation, and Preparation of Combined Drug}

Extraction and isolation of palmatine from stem part of Tinospora cordifolia and stigmasterol from the dried leaves of Azadirachta indica by the method which was already mentioned in our previous studies. After this, an equal quantity of isolated palmatine and stigmasterol were mixed manually to prepare a combined drug sample.

\section{Chemicals, Instruments, and Animals Chemicals}

Croton oil (Sigma-Aldrich), 7, 12-dimethylbenz [a] anthracene, ie, DMBA (Sigma-Aldrich), Ethylene diamine tetraacetic acid ie EDTA (Merck), Nitroblue tetrazolium, ie, NBT (S.D. fine chem. Ltd.), Phenazine methosulphate, ie, PMS (Himedia lab.), Thiobarbituric acid, ie, TBA (Merck) and Trichloroacetic acid, ie, TCA (Merck). Serum biochemical estimation kits (Span Diagnostics Ltd.). All other chemicals/ reagents used were of analytical grade from a reputed firm.

\section{Instruments}

UV-spectrophotometer (EI 2375 Double Beam Spectrophotometer), Incubator (Scientech, SE-128), Autoanalyser (Star 21 plus), and Tissue Homogenizer (REMI, RQ-124A) were used.

\section{Animals}

Swiss albino mice of either sex were carefully chosen casually from the animal stock at the Pinnacle Biomedical Research Institute, Bhopal. The animals were kept in polypropylene cages with sterile husk and had access to standard pellets and water ad libitum during the investigation. The animals were preserved on a 12-hour light/dark cycle at $22^{\circ} \mathrm{C} \pm 2^{\circ} \mathrm{C}$ in an organized environment. All protocols and experiments of the study were done under the Institute Experimental Animal Care Committee at Pinnacle Biomedical Research Institute and tests were accomplished with the preceding approval of the institutional animal ethics committee at Pinnacle Biomedical Research Institute, Bhopal (1283/C/09/CPCSEA).

\section{Determination of Acute Drug Toxicity}

This study is needed before the pharmacological screening of animals. The acute oral toxicity study was carried out 
according to the OECD (Organization for Economic Cooperation and Development) 425 guideline which is based on a stepwise procedure with the use of a minimum number of animals per step. The absence or presence of compound-related mortality of the animal's dose at one step will determine the next step.

Healthy, young Swiss albino mice of either sex (26-30 g) were used for this study. This study was performed on mice using different doses of combined drug samples (200, $400,600,800$, and $1000 \mathrm{mg} / \mathrm{kg}$ ) orally on ten mice. Animals were observed individually at least once during the first 30 minutes after dosing, periodically during the first 24 hours (with special attention given during the first 4 hours) and daily thereafter for a total of 14 days for any sign of alertness, visual placing, passivity, grooming, restlessness, irritability, fearfulness, spontaneous activity, reactivity, tremor, gait, grip strength, pinna, and corneal reflex, touches, pain and startle responses, writhing, defecation, urination, pile erection, heart rate, and respiratory rate. No animal was found to be dead through this toxicity experiment. Now $1 / 5$ th and $1 / 10$ th of the maximum tolerated safe dose was selected for combined drug sample as treatment dose for further pharmacological activity.

\section{Determination of the Synergistic Effect of Combined Drug Sample on DMBA and Croton Oil-Induced Skin Carcinogenesis}

Four different groups of six animals each were taken. Animals of Group I were treated with Milli-Q water $(10 \mathrm{~mL} / \mathrm{kg}$ body weight) and tap water ad libitum with a normal diet daily. At the end of the experiment, this Group I was considered a normal control group. Animals of groups II, III, and IV were treated with a single dose of DMBA over the shaven area of the skin of the animals (dorsally shaved with hair clipper). Two weeks later, Croton oil was applied to the skin of animals as a promoter 3 times per week until the end of the experiment. Group II was considered the carcinogen control group. The combined drug sample which is prepared above was administered orally with the dose of $100 \mathrm{mg} /$ $\mathrm{kg}$ and $200 \mathrm{mg} / \mathrm{kg}$ body weight in the animals of group III and IV, respectively, thrice a week until the end of the experiment (ie, 16 weeks). During the 16 weeks of experimentation, animals of all the groups were observed daily and carefully examined once per week for the weight of animals, number of papillomas, the diameter of the tumor, and average latency period.
Determination of the Synergistic Effect of Combined Drug Sample on Enzymes Involved in Oxidative Stress Tissue Homogenate Preparation

After the collection of blood samples the animals of all the groups were sacrificed by cervical dislocation. The dorsal skin affected by tumors was quickly excised and washed thoroughly with chilled saline. It was then weighed and blotted dry. Tissue homogenate was prepared from part of the sample (skin) in Tris- $\mathrm{HCl}$ and the homogenate was then centrifuged for 15 minutes. The supernatant thus obtained was taken for estimation of the following tissue biochemical markers.

\section{Lipid Peroxidation (LPO)}

The level of LPO was estimated using the method of Ohkawa et al. Briefly, the tissues were homogenized in $0.1 \mathrm{M}$ phosphate buffer $\mathrm{pH} 7.4$ with a Teflon glass homogenizer. In this homogenate, lipid peroxidation was determined by measuring the amounts of malondialdehyde (MDA) produced primarily. $0.2 \mathrm{~mL}$ of tissue homogenate, $0.2 \mathrm{~mL}$ of $8.1 \%$ of sodium dodecyl sulfate (SDS), $1.5 \mathrm{~mL}$ of $20 \%$ acetic acid, and $1.5 \mathrm{~mL}$ of $8 \%$ TBA were added. The volume of the mixture was made up of $4 \mathrm{~mL}$ with distilled water and then heated at $95^{\circ} \mathrm{C}$ on a water bath for 60 min using a glass ball as a condenser. After incubation, tubes were cooled to room temperature and the final volume was made to $5 \mathrm{~mL}$ in each tube. $5 \mathrm{~mL}$ of butanol: pyridine (15:1) mixture was added and the contents were vortexed thoroughly for $2 \mathrm{~min}$. After centrifugation at $3000 \mathrm{rpm}$ for $10 \mathrm{~min}$, the upper organic layer was taken and its optical density (OD) reads at $532 \mathrm{~nm}$ against an appropriate blank without the sample. The level of lipid peroxides was expressed as $\mathrm{n}$ moles of thiobarbituric acid reactive substances (TBARS)/mg protein using an extinction coefficient of $1.56 \times 105 \mathrm{~mol} . \mathrm{L}-1 / \mathrm{cm}^{11}$

\section{Reduced Glutathione (GSH)}

The level of GSH was estimated using the method of Sapakal et al. Tissue homogenate was prepared. 0.1 M phosphate buffer $7.4 \mathrm{pH}, 0.2 \mathrm{~mL}$ of homogenate, $0.2 \mathrm{~mL}$ of $20 \%$ TCA and $0.2 \mathrm{~mL}$ of $1 \mathrm{mM}$ EDTA was taken; then, it was set aside for $5 \mathrm{~min}$ and was centrifuged for $10 \mathrm{~min}$ at $2000 \mathrm{rpm}$ supernatant, $200 \mu \mathrm{L}$ was taken and transferred to a new tube and then $1.8 \mathrm{~mL}$ of Ellman's reagent [5,5-dithio bis 2- nitrobenzoic acid $(0.1 \mathrm{~mL})$ prepared in $0.3 \mathrm{M}$ phosphate buffer, $\mathrm{pH} 7$ with $1 \%$ sodium citrate solution] was added. Volume was made up to $2 \mathrm{~mL}$ 
with distilled water; then, OD was taken at $412 \mathrm{~nm}$ (water as a blank). The result was expressed as in $\mathrm{mM} / \mathrm{mg}$ of protein. ${ }^{12,13}$

\section{Catalase (CAT)}

The CAT was assayed by the method of Aebi. $100 \mu \mathrm{L}$ of supernatant was added to the cuvette containing $1.9 \mathrm{~mL}$ of 50 $\mathrm{mM}$ phosphate buffer ( $\mathrm{pH} 7.0)$. The reaction was started by the addition of $1.0 \mathrm{~mL}$ of freshly prepared $30 \mathrm{mM} \mathrm{H} 2 \mathrm{O} 2$. A decrease in absorbance was read at $240 \mathrm{~nm}$ for $3 \mathrm{~min}$ at an interval of $30 \mathrm{sec}$. The activity was calculated using an extinction coefficient of $\mathrm{H} 2 \mathrm{O} 20.041 \mathrm{micromole} / \mathrm{cm} 2$. Results were expressed as a micromole of $\mathrm{H} 2 \mathrm{O} 2 \mathrm{utilized} / \mathrm{min} / \mathrm{gm}$ tissue. The rate of decomposition of $\mathrm{H} 2 \mathrm{O} 2$ was measured spectrophotometrically by changes in absorbance at $240 \mathrm{~nm} .{ }^{14}$

\section{Superoxide Dismutase (SOD)}

The SOD was assayed by the method of Sapakal et al $10 \% \mathrm{w} / \mathrm{v}$ of tissue homogenate in $0.15 \mathrm{M}$ Tris $\mathrm{HCl}$ or $0.1 \mathrm{M}$ phosphate buffer was prepared and centrifuged at 15,000 rpm for $15 \mathrm{~min}$ at $4 \mathrm{oC}$ then $0.1 \mathrm{~mL}$ of supernatant, $1.2 \mathrm{~mL}$ sodium pyrophosphate buffer ( $\mathrm{pH} 8.3,0.052 \mathrm{M}), 0.1 \mathrm{~mL}$ phenazine methosulphate $(186 \mu \mathrm{M}), 0.3 \mathrm{~mL}$ of $300 \mu \mathrm{M}$ nitro blue tetrazolium (NBT), $0.2 \mathrm{~mL} \mathrm{NADH}(750 \mu \mathrm{M})$ was taken and incubated at $30 \mathrm{oC}$ for $90 \mathrm{sec}$ then $0.1 \mathrm{~mL}$ of glacial acetic acid was added. Stirred with $4 \mathrm{~mL}$ of n-butanol. Allowed to stand for $10 \mathrm{~min}$. Centrifuge and then separate butanol layer and then OD were taken at $560 \mathrm{~nm}$ (butanol as a blank). The result was expressed in terms of $\%$ inhibition of NBT. ${ }^{12}$

\section{Determination of the Synergistic Effect of Combined Drug Sample on Serum Enzyme Analysis}

Blood was obtained from all animals by puncturing the retro-orbital plexus. The blood samples were collected in a fresh Eppendorf and allowed to clot for $45 \mathrm{~min}$ at room temperature. Serum was separated by centrifugation at $7000 \mathrm{rpm}$ at $40 \mathrm{C}$ for $15 \mathrm{~min}$ and used the serum for the estimation of various biochemical parameters, namely Serum Glutamic Oxaloacetic Transaminase (SGOT), Serum Glutamic Pyruvic Transaminase (SGPT), Alkaline Phosphatase (ALP), Serum bilirubin.

\section{Aspartate Aminotransferase (AST)/Serum Glutamic Oxaloacetic Transaminase (SGOT)}

Method: Modified IFCC method
Principle: Optimized UV-test according to the IFCC (International Federation of Clinical Chemistry \& Laboratory Medicine) [modified].

$$
\begin{aligned}
& \text { L-Aspartate }+\alpha \text {-Ketoglutarate } \\
& \stackrel{\text { AST }}{\rightarrow} \text { L-Glutamate }+ \text { Oxaloacetate }
\end{aligned}
$$

Oxaloacetate $+\mathrm{NADH}+\mathrm{H}+\stackrel{\text { MDH }}{\longrightarrow}$ L-Malate $+\mathrm{NAD}+$

Working reagent: For $1 \mathrm{~mL}$ of working reagent mix $800 \mu \mathrm{L}$ of Reagent 1 (Tris-buffer pH 7.8, L-Aspartate, MDH, LD) and $200 \mu \mathrm{L}$ of Reagent 2 ( $\alpha$-ketoglutaric acid, NADH).

Test procedure: Mix $100 \mu \mathrm{L}$ sample in $1000 \mu \mathrm{L}$ working reagent then read absorbance after 1 minute and start the stopwatch. Read absorbance again after 1, 2, and 3 minutes at $37^{\circ} \mathrm{C}$.

Calculation: $\Delta \mathrm{A} / \mathrm{min} \times$ Factor $=$ AST activity $(\mathrm{U} / \mathrm{L})$.

\section{Alanine Aminotransferase (ALT)/Serum Glutamic Pyruvic Transaminase (SGPT)}

Method: Modified IFCC method

Principle: Optimized UV-test according to the IFCC (International Federation of Clinical Chemistry \& Laboratory Medicine) [modified].

L-Alanine $+\alpha$-Ketoglutarate $\stackrel{\text { ALT }}{\rightarrow}$ L-Glutamate + Pyurvate

Pyurvate $+\mathrm{NADH}+\mathrm{H}+\stackrel{\text { LDH }}{\rightarrow}$ L-Lactate $+\mathrm{NAD}+$

Test procedure: Mix $100 \mu \mathrm{L}$ sample in $1000 \mu \mathrm{L}$ working reagent and then read the absorbance after 1 minute and start the stopwatch. Read absorbance again after 1, 2, and 3 minutes at $37^{\circ} \mathrm{C}$.

Calculation: $\Delta \mathrm{A} / \mathrm{min} \times$ Factor $=$ ALT activity $(\mathrm{U} / \mathrm{L})$.

\section{Alkaline Phosphatase (ALP)}

Method: pNNP-AMP (IFCC), Kinetic Assay

Principle: At $\mathrm{pH}$ 10.3, Alkaline Phosphatase (ALP) catalyzes the hydrolysis of colorless p-Nitrophenyl Phosphatase (pNNP) to yellow-colored p-Nitrophenol Phosphatase. Change in absorbance due to yellow color formation is measured kinetically at $405 \mathrm{~nm}$ and is proportional to ALP activity in the Sample.

Working reagent: Prepare "Working Reagent" by reconstituting one vial of Reagent 2 (pNNP Substrate) with Reagent 1 (AMP Buffer) as mentioned below, dissolve properly by gentle swirling. 1 vial of Reagent $2+$ $1.2 \mathrm{~mL}$ of Reagent 1 
Procedure: Mix $20 \mu \mathrm{L}$ serum in $1000 \mu \mathrm{L}$ working ALP Reagent and separate immediately for measurement.

Programmed the analyzer as per assay parameters.

1. Blank the analyzer with purified water.

2. Read absorbance after 30 seconds. Repeat the reading after every 30 seconds, ie, up to 120 seconds at $405 \mathrm{~nm}$ wavelength.

3. Determine the mean absorbance change per minute $(\triangle \mathrm{A} /$ minute)

Calculation: ALP activity $(\mathrm{IU} / \mathrm{L})=\Delta \mathrm{A} /$ minute $\times$ Kinetic factor.

where $\Delta \mathrm{A} /$ minute $=$ Change in absorbance per minute.

Kinetic factor $(\mathrm{K})=2712$.

\section{Total Bilirubin}

Principle: Total bilirubin in serum is determined using Jendrassik and Grof method by coupling with diazotized sulfanilic acid after addition of caffeine, sodium benzoate, and sodium acetate. A blue azobilirubin is formed in alkaline Fehling solution II, which is measured photometrically.

Working reagent: Mix Reagent 1 and Reagent 2 in the ratio $4+1$ (eg, $400 \mu \mathrm{L}$ of sulfanilic acid solution and $100 \mu \mathrm{L}$ of sodium nitrite solution) to make a diazo solution. The mixing ratio should be observed exactly. Always use freshly prepared diazo solution.

Method: Jendrassik and Grof method

Procedure: Performed according to the procedure given below in Table 1.

Calculation: Total bilirubin concentration = $\mathrm{A} \times 10.3 \mathrm{mg} / \mathrm{dl}$.

\section{Statistical Analysis}

Values are recorded as mean \pm SD. The data obtained from different groups were analyzed by One Way ANOVA

Table I Procedure of Total Bilirubin

\begin{tabular}{|l|l|l|}
\hline Pipette into Tube Marked & Sample & Blank Sample \\
\hline Diazo solution & - & $100 \mu \mathrm{L}$ \\
\hline Sulfanilic acid & $100 \mu \mathrm{L}$ & - \\
\hline Accelerator & $500 \mu \mathrm{L}$ & $500 \mu \mathrm{L}$ \\
\hline Serum & $100 \mu \mathrm{L}$ & $100 \mu \mathrm{L}$ \\
\hline Mix and incubate for 30 min. at $37^{\circ} \mathrm{C}$ & $500 \mu \mathrm{L}$ \\
\hline Fehling Solution II & $500 \mu \mathrm{L}$ & \\
\hline $\begin{array}{l}\text { Mix and incubate for } 15 \text { min. at } 37^{\circ} \mathrm{C} . \text { Read absorbance against the } \\
\text { sample blank. }\end{array}$
\end{tabular}

Table 2 Observation of Acute Toxicity Study of Combine Drug Sample

\begin{tabular}{|l|l|l|}
\hline \multirow{2}{*}{$\begin{array}{l}\text { Dose } \\
\text { (mg/kg) }\end{array}$} & \multicolumn{2}{|c|}{ Observations } \\
\cline { 2 - 3 } & $\begin{array}{l}\text { Group III (Dose of } \\
100 ~ \mathbf{~ g g / k g )}\end{array}$ & $\begin{array}{l}\text { Group IV (Dose of } \\
200 ~ \mathbf{~ g} / \mathbf{k g})\end{array}$ \\
\hline 200 & 00000 & 00000 \\
400 & 00000 & 00000 \\
600 & 00000 & 00000 \\
800 & 00000 & 00000 \\
1000 & 00000 & 00000 \\
$L_{50}$ & $>1000 \mathrm{mg} / \mathrm{kg}$ & $>1000 \mathrm{mg} / \mathrm{kg}$ \\
\hline
\end{tabular}

using Bonferroni-test of multiple comparisons. The value $\mathrm{P}<0.05$ was considered statistically significant for all conducting experiments. Primer of Biostatistics software was used.

\section{Histological Study}

At the end of the experiment, animals were sacrificed and fresh portions of the skin from each animal were cut rapidly, fixed in neutral buffered formalin $(10 \%)$, then dehydrated using different grades of ethanol $(70 \%, 80 \%$, $90 \%, 95 \%$, and $100 \%$ ). Dehydration was followed by clearing the samples in two changes of xylene. The samples were then impregnated with two changes of molten paraffin wax, embedded and blocked out. The tissue sections $(4-5 \mu \mathrm{m})$ were stained according to the method described by Bancroft and Stevens using conventional histologic stains. ${ }^{14}$ Stained sections of the carcinogen control and treated mice were observed and photographs were taken using an optical microscope (Olympus, Tokyo, Japan) for alterations in architecture and the presence of degeneration, necrosis in the skin.

\section{Results}

\section{Acute Toxicity Study}

Observation of acute toxicity studies is mentioned in Table 2.

\section{Tumor Parameter}

A gradual decrease in body weight was observed in all animals of the different group's Table 3. Animals of drug-treated groups gave a continuous treatment of combined drug sample orally as mentioned above, along with the repeated application of Croton oil and showed a significant reduction in the cumulative number of papillomas and tumor diameter as compared to the 
Table 3 Chemopreventive Effect of Combined Drug Sample Against Skin Carcinogenesis Induced by DMBA and Croton Oil in Mice

\begin{tabular}{|l|l|l|l|l|l|}
\hline \multirow{2}{*}{ Treatment } & \multicolumn{2}{|l|}{ Body Weight (gm) } & \multirow{2}{*}{ Papillomas (n) } & \multirow{2}{*}{ Tumor Size (mm) } & Average Latency Period* \\
\cline { 2 - 3 } & Initial & Final & & & \\
\hline Group I (normal control) & $38.12 \pm 4.23$ & $37.56 \pm 5.43$ & & & $10.10 \pm 5.17$ \\
Group II (carcinogen control) & $26.26 \pm 2.16$ & $22.75 \pm 11.24$ & $10.16 \pm 5.03$ & $2.06 \pm 0.37$ & $18.59 \pm 0.72$ \\
Group III (treated I00 mg/kg) & $28.23 \pm 2.34$ & $23.80 \pm 13.23$ & $1.09 \pm 0.77$ & $0.58 \pm 0.20$ & $19.96 \pm 0.89$ \\
Group IV (treated 200kg/kg) & $27.56 \pm 2.12$ & $22.87 \pm 11.65$ & $0.65 \pm 0.28$ & $0.24 \pm 0.05$ & \\
\hline
\end{tabular}

Notes: *Average latency period: is $\Sigma \mathrm{fx} / \mathrm{n}$; $\mathrm{f}$ is the number of papillomas appearing every week; $x$ is the number of weeks; $n$ is the total number of papillomas.

treated carcinogen control group Table 3 and Figure 1. The latency period was found to be $10.10 \pm 5.17$ weeks in the carcinogens treated control group, whereas it was significantly increased in drug-treated groups. Combined drug sample treated groups showed much better results than the groups treated with the individual isolated drug. The results of both isolated palmatine and stigmasterol were already mentioned in our previous research. ${ }^{15,16}$

\section{Biochemical Investigation of Enzymatic Activity}

The level of lipid peroxidation significantly increased in the DMBA and Croton oil-treated carcinogen control group as compared with the normal control group Table 4. A significant decrease in the level was observed



A

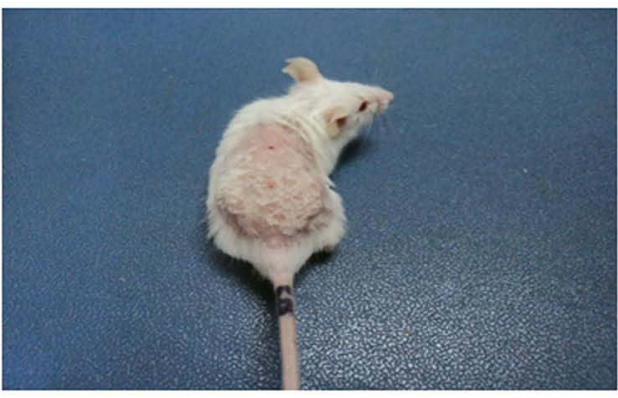

C in the drug-treated groups, as compared to the carcinogen control group. The level of reduced glutathione, superoxide and catalase was significantly decreased in the DMBA and Croton oil-treated carcinogen control group as compared with a normal control group. A significant increase in the level was observed in the drug-treated groups as compared to the carcinogen control group Table 4. Application of DMBA and Croton oil to mice caused damage to the liver, due to their availability in the systematic circulations which increased the level of SGOT, SGPT, ALP, and Bilirubin in the carcinogen control group. The level of SGPT, SGOT, ALP, and Bilirubin was found to be significantly decreased in drug-treated groups as compared to the carcinogen control group Table 5.



B

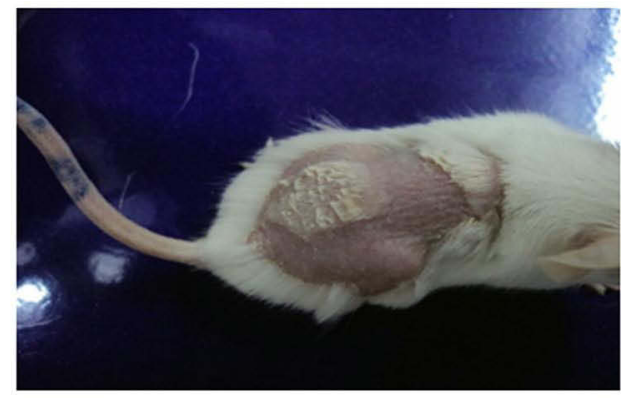

D

Figure I Combine drug sample-induced reduction of tumor in animals: (A) group I: animals treated with water, (B) group 2: animal treated with water, DMBA and Croton oil and examination were made at the end of the experiment, $(\mathbf{C})$ animals treated with DMBA + Croton oil and infusion of a combination drug sample, (D) animal treated with DMBA and Croton oil and infusion of combine drug sample with the increased concentration. 
Table 4 Effect of Combined Drug Sample on Oxidative Enzyme Levels

\begin{tabular}{|l|l|l|l|l|}
\hline Treatment & GSH $\mu \mathrm{mol} / \mathbf{m g}$ Protein & SOD $\boldsymbol{\mu m o l} / \mathbf{m g}$ Protein & Catalase U/mg Protein & LPO nmol/mg Protein \\
\hline Group I (normal control) & $24.28 \pm 1.60^{*}$ & $74.42 \pm 2.06^{*}$ & $36.60 \pm 1.72^{*}$ & $1.82 \pm 0.86^{*}$ \\
Group II (carcinogen control) & $11.02 \pm 0.96$ & $59.59 \pm 2.15$ & $8.97 \pm 1.07$ & $4.82 \pm 1.71$ \\
Group III (treated I00 mg/kg) & $36.15 \pm 0.4 I^{*}$ & $90.03 \pm 1.6 I^{*}$ & $46.23 \pm 1.18^{*}$ & $1.02 \pm 0.5 I^{*}$ \\
Group IV (treated 200 $\mathrm{kg} / \mathrm{kg}$ ) & $38.02 \pm 0.7 I^{*}$ & $92.02 \pm 2.12^{*}$ & $49.11 \pm 1.23^{*}$ & $0.98 \pm 0.56^{*}$ \\
\hline
\end{tabular}

Notes: Each value is the mean \pm standard error of duplicate experiments. $* P<0.05$ vs control.

Abbreviations: GSH, glutathione; SOD, super oxidase dismutase; LPO, lipid peroxidase.

Table 5 Effect of Combined Drug Sample on Serum Enzymes and Bilirubin Levels in Treated Groups

\begin{tabular}{|l|l|l|l|l|}
\hline Treatment & AST IU/L & ALT IU/L & ALP IU/L & Bilirubin mg/dL \\
\hline Group I (normal control) & $58.33 \pm 1.47^{*}$ & $34.45 \pm 1.75^{*}$ & $30.29 \pm 0.73^{*}$ & $1.12 \pm 0.03^{*}$ \\
Group II (carcinogen control) & $162.73 \pm 6.33$ & $149.06 \pm 4.6$ & $231.52 \pm 9.03$ & $5.56 \pm 1.53$ \\
Group III (treated I00 mg/kg) & $79.45 \pm 2.23^{*}$ & $46.54 \pm 1.09^{*}$ & $50.61 \pm 4.2 I^{*}$ & $1.89 \pm 0.68^{*}$ \\
Group IV (treated $200 \mathrm{mg} / \mathrm{kg}$ ) & $70.32 \pm 1.89^{*}$ & $38.78 \pm 0.65^{*}$ & $42.49 \pm 5.63^{*}$ & $1.21 \pm 0.12^{*}$ \\
\hline
\end{tabular}

Notes: Each value is the mean \pm standard error of duplicate experiments. $* P<0.05$ vs control.

Abbreviations: AST, aspartate aminotransferase; ALT, alanine aminotransferase; ALP, alkaline phosphatase.

\section{Histopathology}

Normally, skin epidermis of mice contains three cell layers and small inter-follicular regions in the skin and it has no rete ridges (Figure 2A). We found no change in Group 1: animals received a normal diet on the other had papilloma with signs of an abnormal architecture of the epidermal layer and irregular proliferation of stratum spinosum cells, with abnormal thickening of the stratum corneum and stratum spinosum was observed in Group 2: animals with topical exposure of DMBA and croton oil (Figure 2B). On the other hand, the epidermal damage was repaired in animals treated with DMBA + croton oil and infusion of a combination drug sample (Figure 2C), and repairing of skin epidermal damage increased as drug concentration increased (Figure 2D). Most importantly, the results of skin carcinogenesis and enzymatic activity of combined drug sample treated groups were much better than the groups treated with the individual isolated stigmasterol

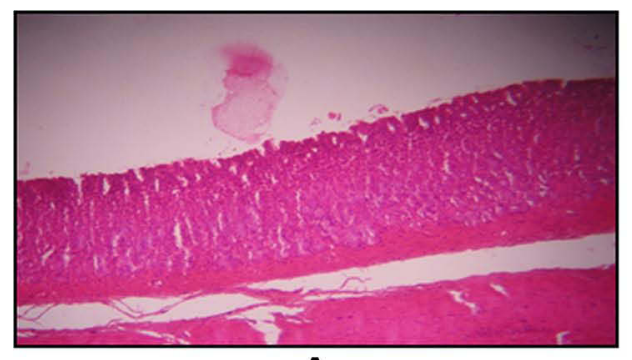

A

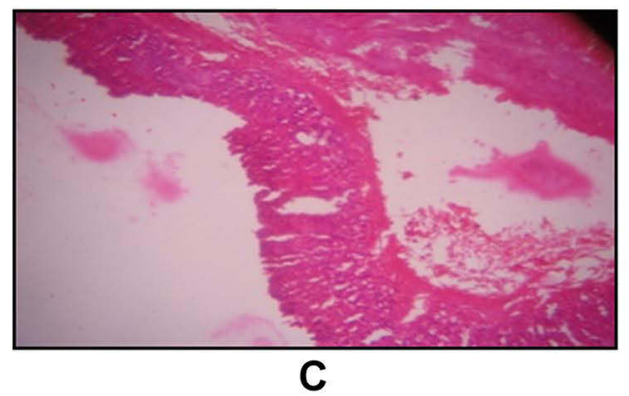

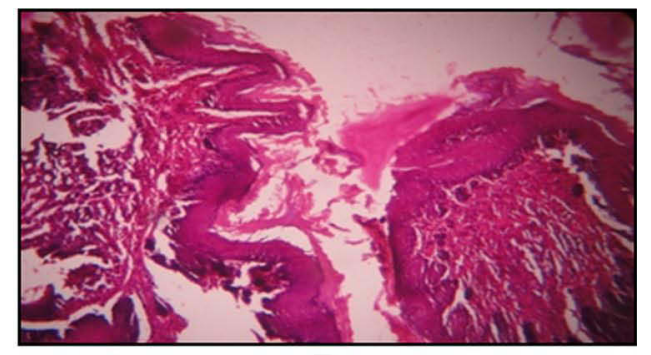

B

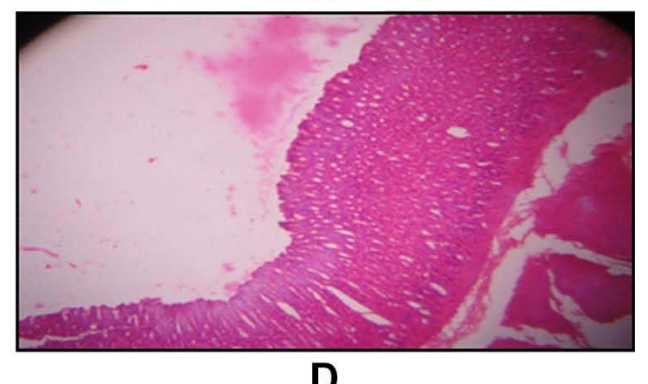

Figure 2 Light of microphotographs of crossed sections of animals skin (A) Group I: animals received a normal diet, (B) Group 2: animals with topical exposure of DMBA and croton oil, (C) Group 3: animals with topical exposure of DMBA+ croton oil and an oral dose of $100 \mathrm{mg} / \mathrm{kg}$ combine drug sample and (D) Group 4: animals with topical exposure of DMBA+ croton oil and an oral dose of $200 \mathrm{mg} / \mathrm{kg}$ combine drug sample. 
and palmatine drugs. The results of these individual drugtreated groups were already mentioned in our earlier research. ${ }^{15,16}$

\section{Discussion}

The present investigation was carried out to discover the anticancer potential of combined drug samples against skin cancer using a two-stage carcinogenesis model which has been achieved. Treatment of cancer is still an obstacle for the medical consultant. Epidemiological evidence recommends that alimentary features play a significant role in social health and the cure of certain chronic diseases as well as cancer. Synergy is a procedure in which some constituents collaborate to the extent of a combined effect that is more than the sum of their separate effects. It is a natural approach that has been developed by nature to obtain more efficiency at a low price. Synergistic effects may be perceived in the interaction between herbal medicine and conventional drugs or phytochemical compounds. ${ }^{4}$

Bahmani et al evaluated the synergistic effect of hydroalcoholic extracts of Origanum vulgare and Hypericum perforatum against the antibacterial activity. They also reported that a combination of their active components, carvacrol, and hypericin also strengthen the activity against Staphylococcus aureus. ${ }^{17}$ Some studies mentioned that a combination of different essential oils with antibiotics showed a synergistic effect against bacteria. ${ }^{18}$ Screening of extracts from Cucumis myriocarpus, Ekebergia capensis, Protea caffra, Bolusanthus speciosus, Prunus Africana, Searsia lancea, and Solanum panduriforme for antigonococcal activity using agar disk diffusion method. Vambe et al finding indicated that a combination of these extracts shows a synergistic effect against Gram-negative bacterial strains with different antibiotics. ${ }^{19}$ Shareef et al studied the synergistic effect of methanol extract Lawsonia inermis, ethanol extract of Punica granatum, the volatile oil of Sesamum indicum, and Arachis hypogaea against Gram-positive and Gram-negative bacteria. $^{20}$ The interaction between the methanol extract of Ziziphus mucronata and antibiotics against bacteria enhanced the antibacterial activity. ${ }^{21}$ One of the studies of Wess et al reported that a combination of four drugs (axitinib, erlotinib, dasatinib, and AZD4547) was significantly more potent for cancer treatment than monotherapies of all single drugs. ${ }^{22}$ The experimental results of Chen et al's study confirmed that both in vitro and in vivo the sequential release of cisplatin and norcantharidin was attained by the combination of coordination connections and hydrolyzable ester bond with synergistic efficiency of cancer prevention. ${ }^{23}$

The isobole method is the most convenient and experimentally suitable method of evaluating synergistic effects. This method involves three different isobole curves; No interaction curve (this is an additive straight line curve in which the effect of two compounds are the simple sum of the single effects, which means they do not interact), synergistic curve (this is the concave-shaped curve which shows synergistic effect where the effects of two compounds are more than the simple sum of the single effects when the two compounds are given together), antagonistic curve (this is convex shape curve which is
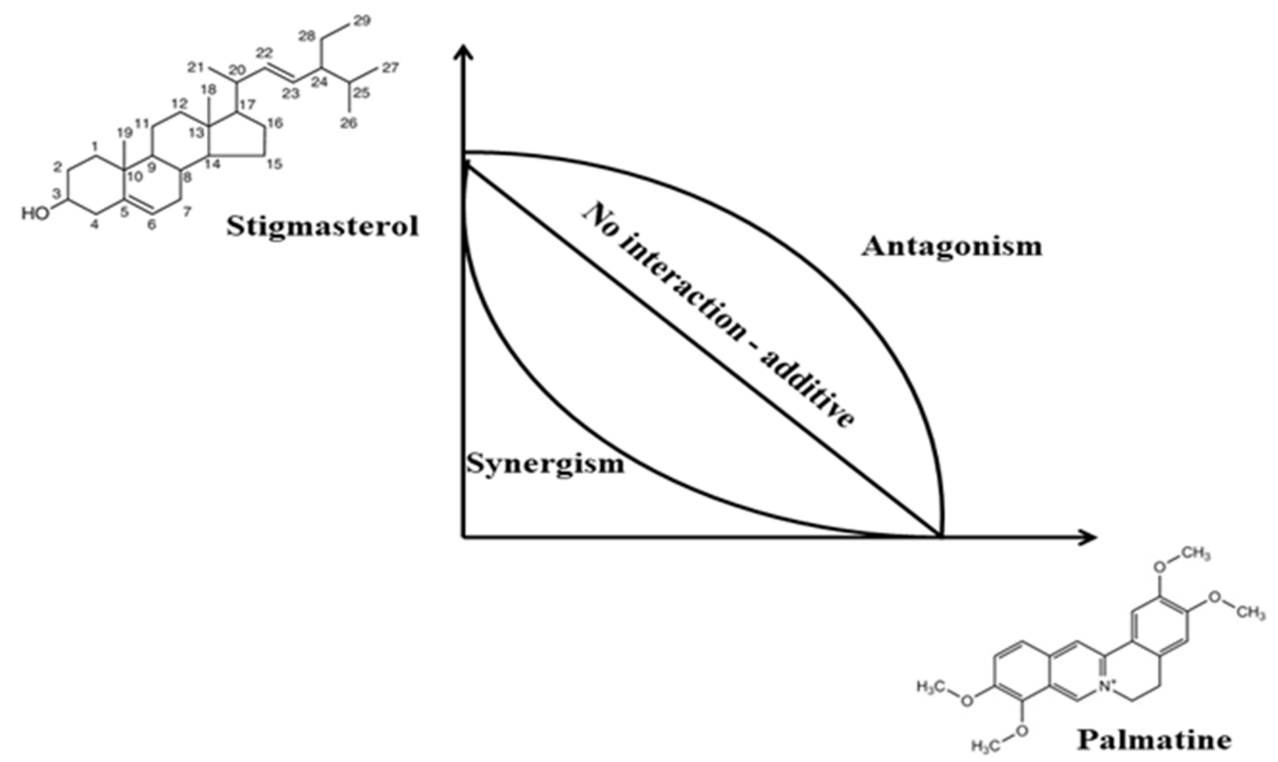

Figure 3 Representation of isobole method. 
opposite of the synergistic effect that is the effects of two compounds are less than the simple sum of the single effect). ${ }^{24}$ In this study, combined drug samples (stigmasterol and palmatine in equal proportion) showed a synergistic curve (Figure 3) which is more effective against skin carcinogenesis as compared when these individual drugs were given separately.

\section{Conclusion}

Herbal medicine and ethnopharmacology have improved in popularity in the last periods, mainly when considering their application in the vast field of human diseases. In conclusion, our results indicate that the extraction and isolation of palmatine and stigmasterol from Azadirachta indica and Tinospora cordifolia, respectively, and the formation of their combined drug sample showed synergistic effects against skin carcinogenesis. A combined drug sample could notably enhance the levels of the antioxidant enzyme and inhibited the lipid peroxidation level. Both enzyme activities and the histological study showed that environmental carcinogens that persuade skin papillomas can be repressed by oral administration of combined drug samples in the everyday diet to attain some defense against skin carcinogenesis. The results of the above study suggest that the above-mentioned combined drug sample has a high impact as a therapeutic agent, and is more effective for the treatment of skin carcinogenesis.

\section{Acknowledgment}

This research was funded by the Deanship of Scientific Research at Princess Nourah bint Abdulrahman University through the Fast-track Research Funding Program to support publication in the top journal (Grant no. 42-FTTJ-55).

\section{Disclosure}

The authors report no conflicts of interest for this work.

\section{References}

1. Doos L, Roberts EO, Corp N, Kadam UT. Multi-drug therapy in chronic condition multimorbidity: a systematic review. Fam Pract. 2014;31:654-663.

2. Bao M, Zhang L, Liu B, et al. Synergistic effects of anti-MRSA herbal extracts combined with antibiotics. Future Microbiol. 2020;15 (13):1265-1276. doi:10.2217/fmb-2020-0001

3. Wagner H. New targets in the Phytopharmacology of Plants. In: Herbal medicine, a concise overview for healthcare professionals. Butterworth-Heinemann; 1999:34-42.

4. Pezzani R, Salehi B, Vitalini S, et al. Synergistic effects of plant derivatives and conventional chemotherapeutic agents: an update on the cancer perspective. Medicina (Kaunas). 2019;55:110. doi:10.3390/ medicina55040110
5. Williamson EM. Synergy and other interactions in phytomedicines. Phytomedicine. 2001;8:401-409. doi:10.1078/0944-7113-00060

6. Varghese CD, Nair S, Panikkar B, Panikkar KR. Effect of Asoka on the intracellular glutathione levels and skin tumor promotion in mice. Cancer Lett. 1993;69:45-50. doi:10.1016/0304-3835(93)90031-4

7. Dev S. Natural product in medicine - present status and future prospects. Curr Sci. 1983;52:947-956.

8. Moussaoui E, Jawhari FZ, Almehdi AM, Elmsellem H, Bari A. Antibacterial, antifungal and antioxidant activity of total polyphenols of Withania frutescens.L. Bioorg Chem. 2019;93:103337. ArticleID 103337. doi:10.1016/j.bioorg.2019.103337

9. Mukherjee PK. Promotion and Development of Botanicals with International Coordination. India: Allied Book Agency; 2005.

10. Mukherjee PK, Rai S, Bhattacharya S, Wahile A, Saha SP. Marker analysis of polyherbal formulation, Triphala - a well known Indian traditional medicine. Indian J Tradit Knowl. 2008;7:379-383.

11. Ohkawa H, Ohishi N, Yogi K. Assay of lipid peroxidation in animal tissue by thiobarbituric acid reaction. Anal Biochem. 1979;95:351-358. doi:10.1016/0003-2697(79)90738-3

12. Sapakal VD, Shikalgar TS, Ghadge RV, Adnaik RS, Naikwade NS, Magdum CS. In vivo screening of antioxidant profile: a review. J Herb Med Toxicol. 2008;2:1-8.

13. Moron MA, Depierre JW, Mannervick B. Levels of glutathione, glutathione reductase and glutathione S-transferase activities in rat lung and liver. Biochim Biophys Acta. 1979;582:67-78. doi:10.1016/ 0304-4165(79)90289-7

14. Aebi H. Methods in Enzymology. New York: Published by Academic Press; 1984.

15. Ali H, Dixit S, Ali D, Alqahtani SM, Alkahtani S, Alarifi S. Isolation and evaluation of anticancer efficacy of stigmasterol in a mouse model of DMBA-induced skin carcinoma. Drug Des Devel Ther. 2015;9:2793-2800. doi:10.2147/DDDT.S83514

16. Ali H, Dixit S. Extraction optimization of tinospora cordifolia and assessment of the anticancer activity of its alkaloid palmatine. Sci World J. 2013;2013:1-10. Article ID 376216: 10. doi:10.1155/2013/376216

17. Bahmani M, Taherikalani M, Khaksarian M, et al. The synergistic effect of hydroalcoholic extracts of Origanum vulgare, Hypericum perforatum and their active components carvacrol and hypericin against Staphylococcus aureus. Future Sci. 2019;5:FSO371.

18. Moussaoui F, Alaoui T. Evaluation of antibacterial activity and synergistic effect between antibiotic and the essential oils of some medicinal plants. Asian Pac J Trop Biomed. 2016;691:32-37. doi:10.1016/j.apjtb.2015.09.024

19. Vambe M, Aremu AO, Chukwujekwu JC, Finnie JF, Van Staden J. Antibacterial screening, synergy studies and phenolic content of seven South African medicinal plants against drug-sensitive and resistant microbial strains. $S$ Afr J Bot. 2018;114:250-259. doi:10.1016/j.sajb.2017.11.011

20. Sharif S, Ismaeil A, Ahmad A. Synergistic effect of different plant extracts and antibiotics on some pathogenic bacteria. Sci J Univ Zakho. 2020;8:7-11. doi:10.25271/sjuoz.2020.8.1.653

21. Olajuyigb AA, Olajuyigbe OO, Coopoosamy RM. Interaction of Ziziphus mucronata subsp. mucronata methanol extract and first line antibiotics is synergistic in vitro through production of reactive oxygen species. J Trop Med. 2020;2020:Article ID 4087394. doi:10.1155/2020/4087394

22. Weiss A, Berndsen RH, Ding X, et al. A streamlined search technology for identification of synergistic drug combinations. Sci Rep. 2015;5(1):1-11. doi:10.1038/srep14508

23. Chen M, Zhu X, Yan D. Sequential drug release for synergistic cancer treatment and immunity promotion. $R S C A d v$. 2013;3: 13399-13405. doi:10.1039/c3ra41437j

24. Katselou MG, Matralis AN, Kourounakis AP. Multi-target drug design approaches for multifactorial diseases: from neurodegenerative to cardiovascular applications. Curr Med Chem. 2014;21: 2743-2787. doi:10.2174/0929867321666140303144625 


\section{Publish your work in this journal}

Drug Design, Development and Therapy is an international, peerreviewed open-access journal that spans the spectrum of drug design and development through to clinical applications. Clinical outcomes, patient safety, and programs for the development and effective, safe, and sustained use of medicines are a feature of the journal, which has also been accepted for indexing on PubMed Central. The manuscript management system is completely online and includes a very quick and fair peer-review system, which is all easy to use. Visit http://www. dovepress.com/testimonials.php to read real quotes from published authors. 